\title{
Design and Build Color Detection Tool Prototype with Arduino Uno
}

\author{
Samsu Tuwongkesong \\ Electrical Engeenering Dept \\ Manado State Polytechnic \\ North Sulawesi - Indonesia \\ Muchdar D. Patabo \\ Information Technology Dept \\ Manado State Polytechnic \\ North Sulawesi - Indonesia
}

\author{
Anthoinete P.Y. Waroh \\ Electrical Engeenering Dept \\ Manado State Polytechnic \\ North Sulawesi - Indonesia
}

\author{
Tony J. Wungkana \\ Electrical Engeenering Dept \\ Manado State Polytechnic \\ North Sulawesi - Indonesia
}

\begin{abstract}
The ball sorting process still uses the manual method, while this method is often inaccurate and the results vary due to the different perceptions of each person. In line with the development of science and technology today, the sorting process has been developed with automatic systems for effectiveness in use, as well as accuracy. the results obtained. This study aims to make a ball sorting prototype with a TCS3200 color sensor to distinguish ball colors using an Arduino Uno microcontroller as a control tool. The detected ball color information is displayed on the LCD.

The method used is the Prototype Design Method starting at the stage of literature study and data collection. Continued software and hardware design for the needs of color detection devices, then the stage of making a control system on the prototype, then the testing stage. Prototype This color detector works by detecting the color of the ball, after being detected by the TCS200 sensor, the servo motor will direct the ball to the shelter (box) according to the color of the ball.
\end{abstract}

\section{General Terms}

Ball Color, Sorting

\section{Keywords}

Arduino Uno, LCD, Sensor TCS3200 and Motor Servo

\section{INTRODUCTION}

Technology is growing and technological developments can be felt by all people, where technology is the result of increasingly advanced human civilization, which is felt to be very helpful and easier for humans to fulfill their needs.

One technology that can work automatically is the TCS3200 color sensor which is used for various needs, one of which is to find out the analysis of several color objects that are brought closer to the sensor to distinguish several types of selected color objects, to know how the color sensor works, so that the color sensor can work as needed. obtained color.

For basic color detection using phototransistor and LDR, it does not get the desired result. For this reason, a sensor that is sensitive to color changes in the base color is needed.

Based on this, we will create a prototype tool that can detect the color of the ball and place it in the color box with the Arduino Uno Microcontroller control device.

\section{LITERATURE REVIEW}

\subsection{Sensor TCS3200}

The TCS3200 color sensor is a programmed sensor consisting of 64 photodiodes as a detector of light intensity on the color of an object and a frequency filter as a transducer that functions to convert current into frequency. In addition, the sensor has a focus lens that is useful for sharpening the detection of photodiodes against light intensity with a reading distance of $2 \mathrm{~mm}$ from the IC lens.

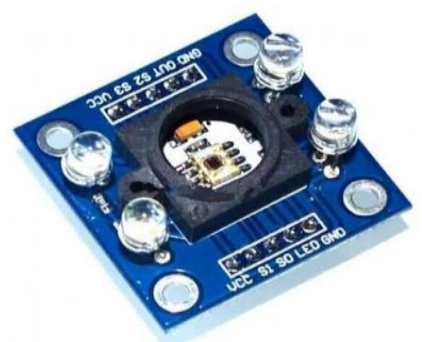

Figure 1. Color Sensor TCS3200

The TCS3200 color sensor can read 4 color modes, namely, red, green, blue, and clear through 64 photodiodes which are divided into 4 parts, namely 16 photodiodes for red, 16 photodiodes for green, 16 photodiodes for blue, and 16 other photodiodes. for clear color reading.

\subsection{Arduino Uno Microcontroller}

Arduino Uno with ATMega328P has 14 digital inputs/outputs (6 of which can be used for PWM output), 6 analog inputs, $16 \mathrm{MHz}$ clock speed, USB connection, power jack, ICSP header, and reset button. Arduino Uno ATMega328P schematic.

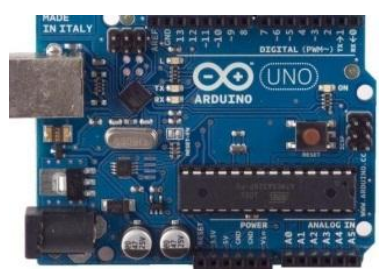

Figure 2. Skema Arduino Uno 


\subsection{Servo Motor}

Servo motor is an electric motor using a closed loop system. The system is used to control the acceleration and speed of an electric motor with high accuracy.

In addition, servo motors are commonly used to convert electrical energy into mechanical energy through the interaction of the two permanent magnetic fields.

In general, servo motors consist of three main components, namely:
a. Motorcycle
b. Control system
c. Potentiometer or encoder.

The motor functions as a gear drive so that it can rotate the potentiometer and its output shaft simultaneously.
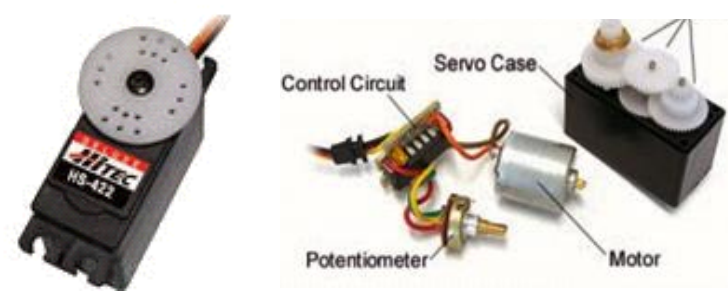

Figure 3. ServoMotor

\subsection{Liquid Crystal Display (LCD)}

LCD is an electronic circuit that is used to display information or indicators given to the microcontroller. The LCD used is a dot matrix LCD with a character count of $2 \times 16$. The LCD is very functioning as a viewer which will later be used to display the working status of the tool.

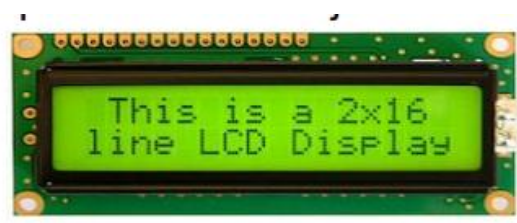

Figure 4. Liquid Cystal Display

\subsection{I2C LCD}

I2C LCD is an LCD module that is controlled serially in sync with the I2C/IIC (Inter Integrated Circuit) or TWI (Two Wire Interface) protocol. LCD modules are normally controlled in parallel for both the data and control lines. The I2C converter module shown in Figure 5 uses the ICPCF8574 chip from NXP as the controller. This IC is an 8 bit I/O expander for the $\mathrm{I} 2 \mathrm{C}$ bus which is basically a shift register.

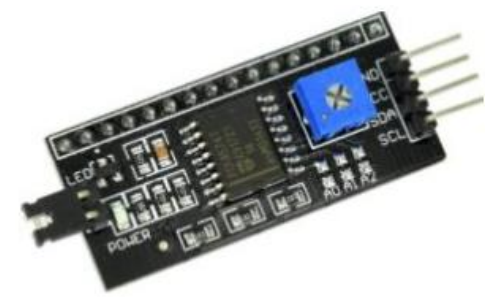

Figure 5. LCD I2C Module

\section{METHODOLOGY}

In this study, the design method is used, begins with making a block diagram of the system and the design of the color detection device system then processed by the Arduino Uno microcontroller, the results are displayed on the LCD.

The design done by: Making control system block diagrams, designing power supply, TCS3200 Color Sensor, Servo Motor, Led Indicator using Arduino Uno microcontroller and Monitoring with LCD as well as testing an integrated control system to simplify the hardware manufacturing process.

The stages of the research are described as the block diagram in Figure 6. below:

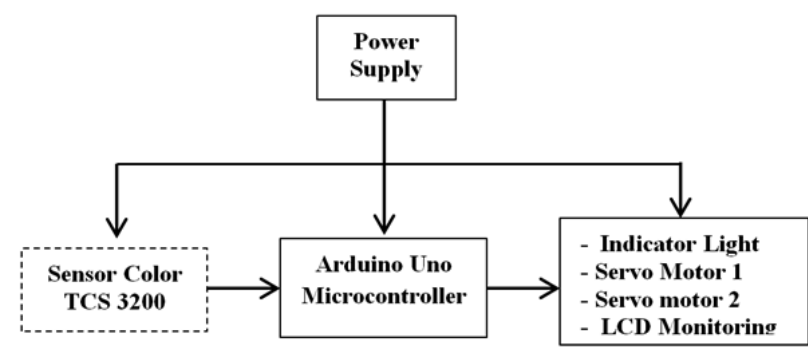

Figure 6. Block Diagram System

Description of block diagram system:

1. Designing a power supply for Sensors, Arduino Uno, Servo Motors and LCD monitoring tools.

2. Designing the TCS3200 Color Sensor to detect the color of the ball.

3. Implementation of the Arduino Uno Microcontroller as a central control system that functions to receive data from sensors and process the data.

4. Designing a series of Servo1 and Servo2 Motors as a rail drive to move the color of the ball on the box.

5. Designing LCD (Liquid Crystal Display) and indicator light (Led) for system monitoring. 


\subsection{Research Model And Design}

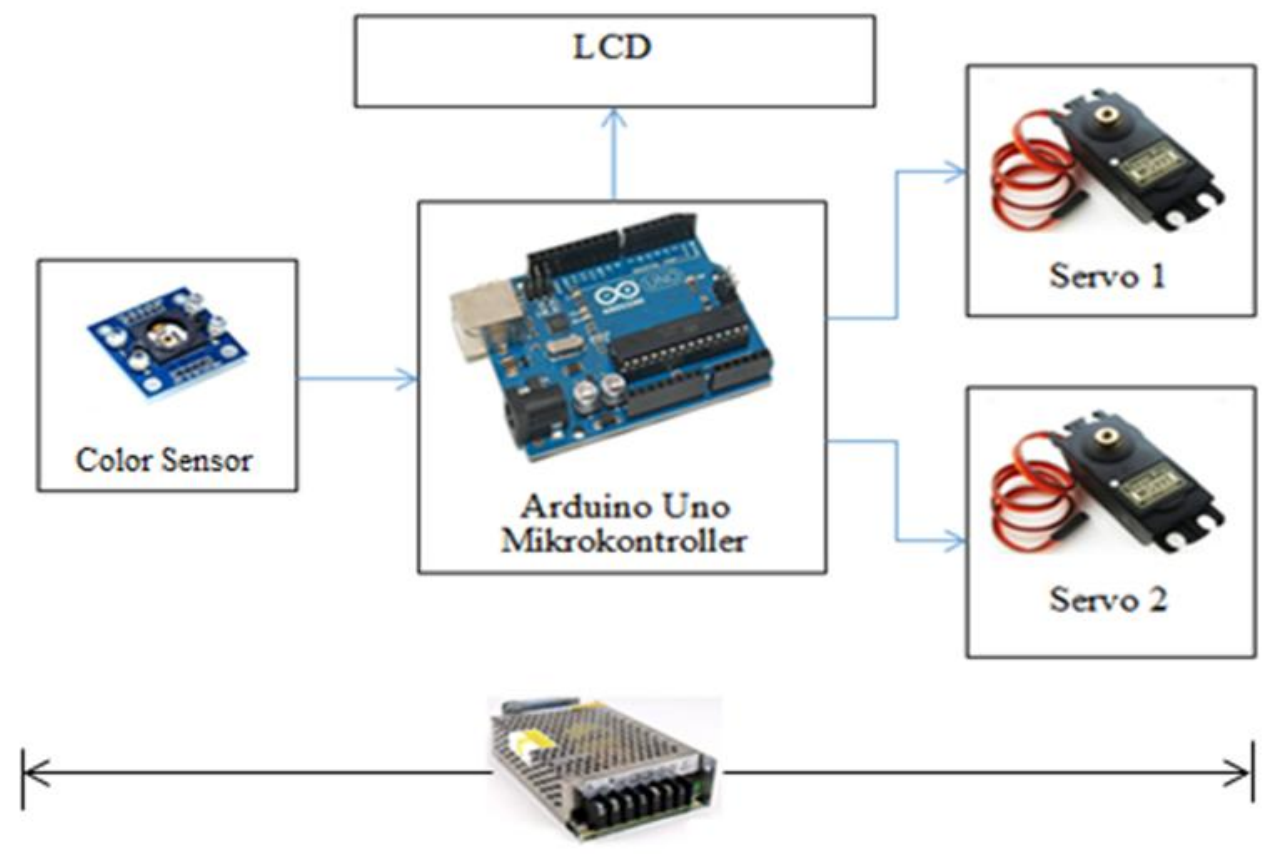

Figure 8. Color Detection System

How the System works:

When the system is activated, the Arduino Uno Microcontroller will detect a signal from the TCS3200 Color Sensor to detect the color of the ball. Furthermore, Arduino Uno is processed to move the ball color sorter on the ball shelter rail according to the ball color. Besides, the output of Arduino Uno displays the color of the ball detected through the LCD.

\section{FLOW CHART SYSTEM}

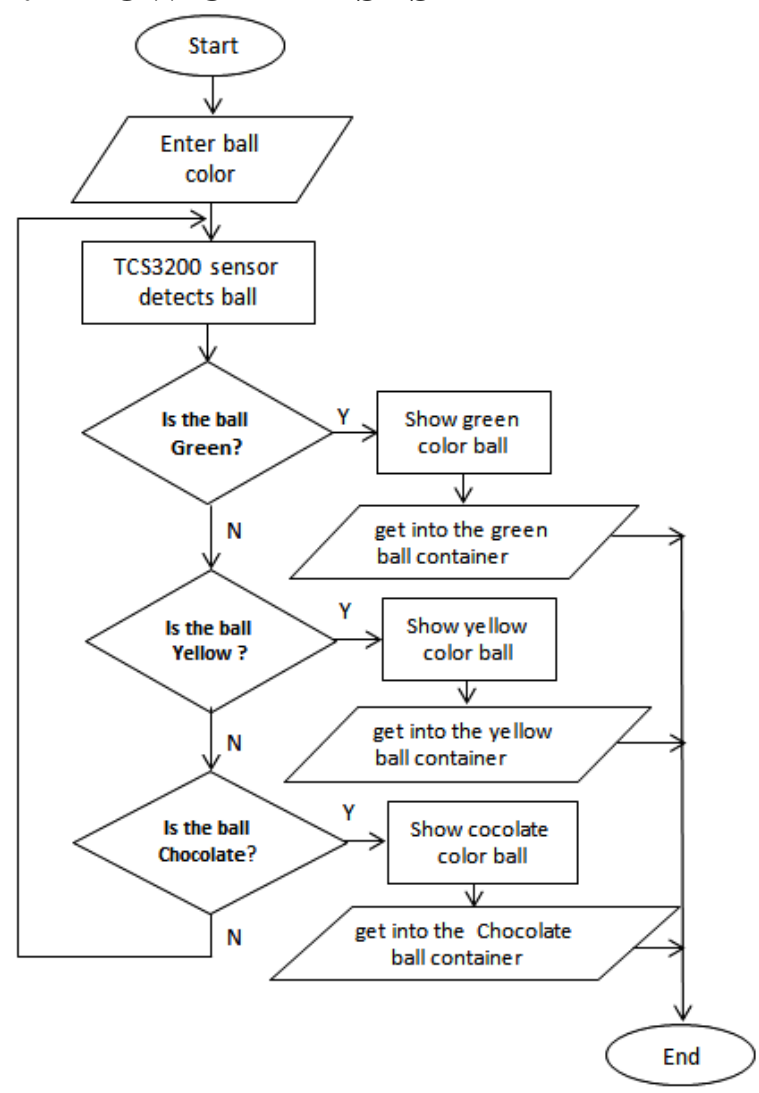

Figure 9. Flow Chart of Color Detection System System Flow Chart Description: 
1. Turn on the system

2. Read Color sensor signal.

3. Displays color of the ball on the LCD.

4. If the ball is red, the servo motor will move the rail to the red shelter.

5. If the ball is yellow the servo motor will move the rail to the yellow shelter.

6. If the ball is green the servo motor will move the rail to the green shelter.

\section{RESULT AND DISCUSSION}

In this section, we will discuss the test steps which include testing the TCS3200 Color Sensor circuit, Arduino Uno Microcontroller, Servo Motor, testing the I2C LCD circuit.

\subsection{Liquid Crystal Display}

LCD testing was carried out using the Arduino Uno microcontroller as a control to run the program displaying characters on the LCD. The program is made using the C language program with Arduino 1.0.6 software.

Listing of LCD programs as follows:void setup() \{

Serial.begin(9600);

lcd.begin(16,2); // initialize the lcd for 16 chars 2 lines

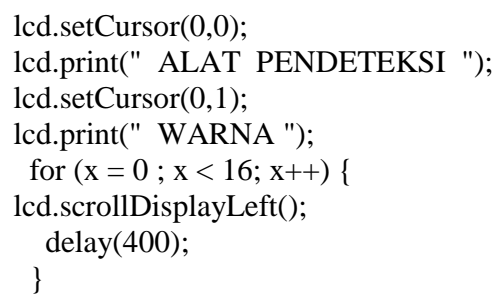

After the program is completed and verified there is no syntax error in the program, the program is uploaded so that it obtains the program used to run the microcontroller.

The results of the program on the LCD as shown in Figure 11. below:

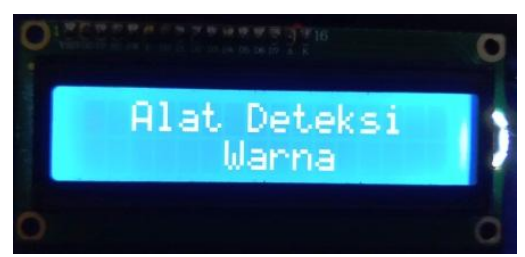

Figure 10. LCD Display Test

In figure 10. It looks like there is a Color Detection Tool inscription which indicates that the LCD is in good condition and ready to be used.

\subsection{Servo Motor Voltage Test}

The purpose of testing the servo motor is to find out whether the servo motor that is connected to the Arduino Uno can work according to the amount of the input angle given.

The motor voltage is measured on the line connecting the stepdown voltage output to ground at $5 \mathrm{~V}$ volts.

Table 1. Testing the servo motor on average for low conditions of $0 \mathrm{~V}$, while the average for high conditions is 4.72 Volts.
Table 1. Servo Motor Test Results

\begin{tabular}{|l|l|l|}
\hline \multirow{2}{*}{ Movement Angle } & \multicolumn{2}{|c|}{ Working Voltage (Vdc) } \\
\cline { 2 - 3 } & Motor Servo 1 & Motor Servo 2 \\
\hline 0 & 4,72 & 4,64 \\
\hline $90^{0}$ & 4,72 & 4,72 \\
\hline $180^{\circ}$ & 4,72 & 4,72 \\
\hline
\end{tabular}

\subsection{Color Sensor TCS3200Testing On LCD Display}

Testing a series of color sensors that have been connected to the Arduino Uno microcontroller and the results are displayed on the LCD.

A fragment of the color program listing is as follows:void detectcolor()

\{

// Setting GREEN (G) filtered photodiodes to be read digitalWrite(S2,HIGH);

digitalWrite(S3,HIGH);

// Reading the output frequency

green $=$ pulseIn $($ sensorOut, LOW $)$;

// Printing the GREEN (G) value

Serial.print(" G = ");

Serial.print(green);

delay (100);

if(blue $<55$ \& \& red $<150 \& \&$ green $<90)\{$

//ketentuan range RGB

warna $=1$; //warna $=1$

Serial.println("Biru"); \}

else if $(($ red $>50 \& \&$ red $<58) \& \&(74<$ green $\& \&$ green $<85) \& \&$

blue $<70)\{/ /$ ketentuan range RGB

warna $=2 ; / /$ warna 2

Serial.println("Merah"); \}

else if $((88<$ red\&\&red $<=95) \& \&(94<$ green $\& \&$ green $<=96)$

$\& \&(83<$ blue $\& \&$ blue $<=88))\{/ /$ ketentuan range RGB

warna $=3$; //warna 3

Serial.println("Hijau"); \}

else if $((45<$ red $\& \&$ red $<56) \& \&(43<$ green $\& \&$ green $<62) \& \&$ $(65<$ blue $\& \&$ blue $<72))\{/ /$ ketentuan range RGB

warna $=4$; //warna 4

Serial.println("Kuning"); \}

else if $((57<$ red $\& \&$ red $<=88) \& \&(63<$ green $\& \&$ green $<=94)$

$\& \&(70<$ blue $\& \&$ blue $<=83))\{/ /$ ketentuan range RGB

warna $=5 ; / /$ warna 5

Serial.println("Coklat"); \}

Else \{

warna $=0$; //Tidak mendeteksi

Serial.println("tidak mendeteksi"); \} \}

Here's the RGB color display on the LCD:

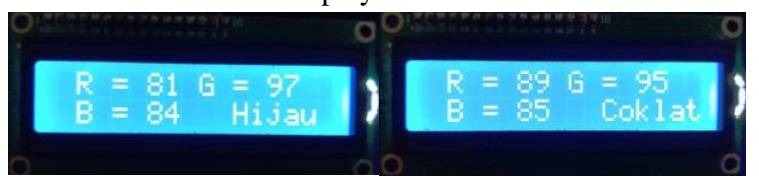

Figure 11. Color Sensor Testing on LCD display

\subsection{Color Detection Tool Test}

Testing is done to determine the function of each component of the tool whether it is in accordance with the flowchart that has been made, so that improvements can be made to obtain results that are in accordance with the design of both hardware and software as in the prototype color detection tool in Figure 14.

The test is carried out to determine (sort) the color of the ball to be included in the specified box. The first test does 
notprovide a voltage source on the servo motor so that the color that will be detected by the TC 3200 sensor does not move, the aim is to calibrate the distance between the sensor and the object based on the color of the ball.

The test is carried out on the serial monitor of the Color Detection Tool program, after the program created is appropriate, the program is verified to ensure there are no errors in the program. Next, the program is uploaded to the Arduino Uno which has been assembled on the prototype of the Color Detection Tool.

To monitor the color results of the ball detected by the TC3200 color sensor by selecting Serial Monitor in the Arduino software. The result is as in Figure 14.

Testing Conducted 15 times the experiment, the results showed 4 times the object was not detected. From the test results, it becomes a reference for determining objects or balls that are green with minimum and maximum numbers on the basic colors red (Red), green (Green), blue (Blue). a minimum of 82 and a maximum of 97 while the Blue color is a minimum of 83 and a maximum of 85 .

The failure rate of ball color reading is caused by light from outside entering the color sensor, so that the ball color calibration is still not correct.

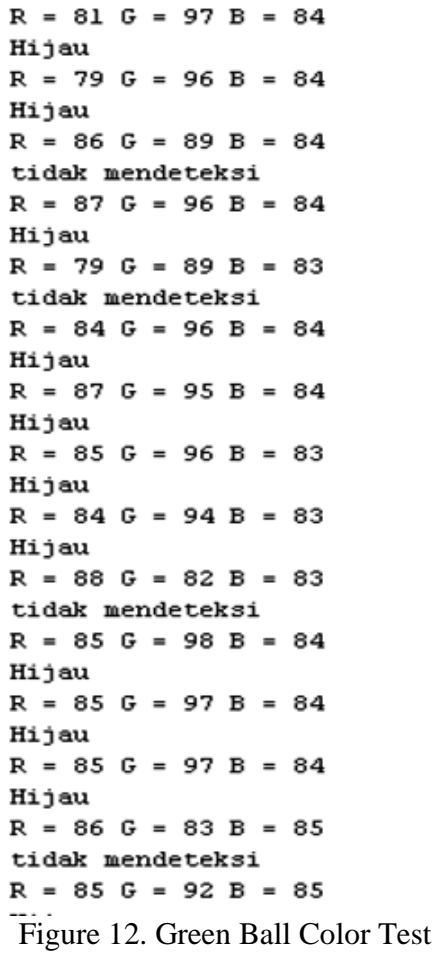

Figure 12. Green Ball Color Test

For testing the yellow ball as shown in Figure 13.

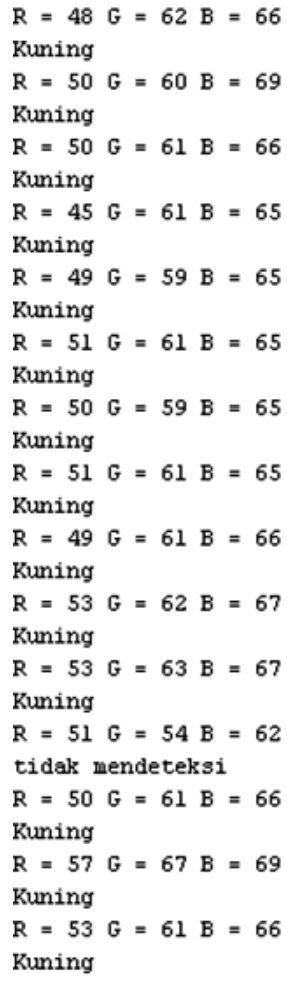

Figure 13. Yellow Ball Color Test

The test was carried out 15 times, the results showed that 1 time the yellow ball was not detected.

The second test is done by applying a voltage to the servo motor. This test is carried out to determine the value of RGB with the same ball color 15 times. The first test is the green ball, from the test results can be seen in table 2 .

Table 2. Green ball second test results

\begin{tabular}{|c|c|c|c|c|}
\hline Test & Red & Green & Blue & Description \\
\hline 1 & 81 & 97 & 84 & Green \\
\hline 2 & 79 & 96 & 84 & Green \\
\hline 3 & 86 & 89 & 84 & Green \\
\hline 4 & 87 & 96 & 84 & Green \\
\hline 5 & 79 & 89 & 83 & Not detected \\
\hline 6 & 84 & 96 & 84 & Green \\
\hline 7 & 87 & 96 & 84 & Green \\
\hline 8 & 85 & 96 & 83 & Green \\
\hline 9 & 84 & 94 & 83 & Green \\
\hline 10 & 88 & 82 & 83 & Green \\
\hline 11 & 85 & 96 & 84 & Green \\
\hline 12 & 85 & 97 & 84 & Green \\
\hline 13 & 85 & 97 & 84 & Green \\
\hline 14 & 85 & 83 & 85 & Green \\
\hline 15 & 85 & 92 & 85 & Green \\
\hline
\end{tabular}

For testing the yellow ball as shown in Figure 4. The test was carried out 15 times, the results showed 1 time the object was not detected so that the percentage of failure was $6.67 \%$.Error $=(|14-15| / 15) \times 100 \%$

$=(1 / 15) \times 100 \%=0.066 \times 100 \%$

$=6.67 \%$

For experiments with yellow balls as in table 3 . 
Table 3. Yellow ball second test results

\begin{tabular}{|c|l|l|l|l|}
\hline Test & Red & Green & Blue & Description \\
\hline 1 & 48 & 62 & 66 & Yellow \\
\hline 2 & 50 & 60 & 69 & Yellow \\
\hline 3 & 50 & 61 & 66 & Yellow \\
\hline 4 & 45 & 61 & 65 & Yellow \\
\hline 5 & 49 & 59 & 65 & Yellow \\
\hline 6 & 51 & 61 & 65 & Yellow \\
\hline 7 & 50 & 59 & 65 & Yellow \\
\hline 8 & 51 & 61 & 65 & Yellow \\
\hline 9 & 49 & 61 & 66 & Yellow \\
\hline 10 & 53 & 62 & 67 & Yellow \\
\hline 11 & 53 & 63 & 67 & Yellow \\
\hline 12 & 51 & 54 & 62 & Not detected \\
\hline 13 & 50 & 61 & 66 & Yellow \\
\hline 14 & 57 & 67 & 69 & Yellow \\
\hline 15 & 53 & 61 & 66 & Yellow \\
\hline
\end{tabular}

The results of the test with a brown ball with 15 trials with a failure rate of $6.6 \%$.

For experiments with brown balls as in table 4 .

Tabel 4.Brown ball Second test results

\begin{tabular}{|c|l|l|l|l|}
\hline Test & Red & Green & Blue & Description \\
\hline 1 & 89 & 95 & 85 & Chocolate \\
\hline 2 & 92 & 89 & 79 & Chocolate \\
\hline 3 & 89 & 69 & 81 & Not detected \\
\hline 4 & 89 & 94 & 85 & Chocolate \\
\hline 5 & 93 & 95 & 85 & Chocolate \\
\hline 6 & 93 & 95 & 85 & Chocolate \\
\hline 7 & 92 & 93 & 85 & Chocolate \\
\hline 8 & 91 & 93 & 86 & Chocolate \\
\hline 9 & 89 & 93 & 85 & Chocolate \\
\hline 10 & 89 & 95 & 85 & Chocolate \\
\hline 11 & 89 & 95 & 85 & Chocolate \\
\hline 12 & 94 & 93 & 85 & Chocolate \\
\hline 13 & 93 & 95 & 85 & Chocolate \\
\hline 14 & 91 & 93 & 85 & Chocolate \\
\hline 15 & 92 & 90 & 86 & Chocolate \\
\hline
\end{tabular}

The results of testing with brown objects with 15 trials, the failure rate was $6.6 \%$

Tabel5. Color Test Results

\begin{tabular}{|c|c|c|c|c|c|c|c|}
\hline \multirow{2}{*}{$\begin{array}{c}\text { No } \\
\cdot\end{array}$} & \multirow{2}{*}{ Color } & \multicolumn{2}{|c|}{ R } & \multicolumn{2}{c|}{ G } & \multicolumn{2}{c|}{ B } \\
\cline { 3 - 8 } & & Min & Max & Min & Max & Min & Max \\
\hline 1. & Green & 79 & 88 & 82 & 97 & 83 & 85 \\
\hline 2. & Yellow & 48 & 57 & 54 & 67 & 62 & 67 \\
\hline 3. & $\begin{array}{c}\text { chocolat } \\
\text { e }\end{array}$ & 89 & 95 & 69 & 94 & 79 & 86 \\
\hline
\end{tabular}

In testing on RGB color, it appears that the Green color has the highest percentage at output $G$, Yellow has the highest percentage at output $\mathrm{B}$ and the highest percentage is Brown at output R.
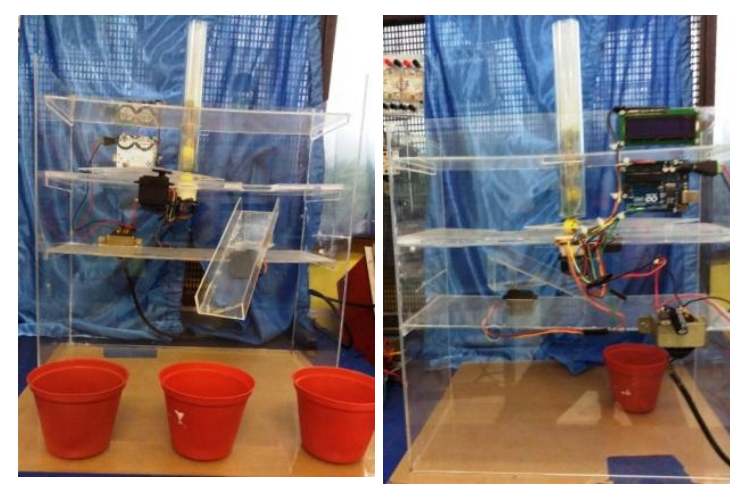

Figure 14. Proto Type Color Detection Tool

In figure 14. If the color detection tool is activated, the TCS3200 color sensor will detect the color of the ball then it will be processed by the Arduino Uno Microcontroller to be displayed on the LCD. The ball is placed in a silo, if there is a ball it will be detected by the color sensor based on the color of the ball and send data to the microcontroller, if the color sensor does not detect the color of the ball then the LCD display will appear undetected, and if the TCS3200 sensor detects a yellow ball then on the screen The LCD will display yellow writing and servo motor 1 will move the ball onto the sorting rail to the yellow container. Likewise, the color of the ball is green and brown.

\section{CONCLUSION}

From the results of the tests done, it can be concluded that the Arduino Uno microcontroller can control the TCS3200 color sensor to detect the color of the ball then it will give a signal to the microcontroller for processing and these results will direct servo 1 to direct the detected ball and bring the ball towards the conveyor or rail. which is directed by servo 2 to the box that matches the color of the ball.

\section{THANK-YOU NOTE}

The authors would like to thank P3M Politeknik Negeri Manado and all those who can not be mentioned one by one so that this research can be done.

\section{REFERENCES}

[1] Arwi Rinaldo, KhazaliFahmi,LasmitaSari, and Hendro, Color Detection Tool Using a TCS230 Sensor Based on the Basic Color of the RGB Composer, PROCEDURE SNIPS 2018, ISBN: 978-602-61045-4-0, 9 - 10 July 2018 , Department of Physics, Faculty of Mathematics and Natural Sciences, Bandung Institute of Technology.

[2] Budhiharto, W.; Interfacing Computers and Microcontrollers; Publisher Elex Media Komputindo, Jakarta. 2017.

[3] Iskandar Zulkarnain, MukhlisRamadhan, Badrul Anwar, Implementation of Object Color Detector Using Fuzzy Logic with Arduino-Based TCS3200 Sensor, J-SISKO TECH (Journal of Information Systems and Computer Systems Technology TGD, ISSN : 2621-8976, E-ISSN : 2615-5133, Vol.2, No.2 July 2019, pp. 106-117.

[4] LediDianto, Journal, "Color Detection Tool Using a TCS3200 Sensor Based on an ATMEGA8535 Microcontroller" Depok, 2011. 
[5] Saiful Widianto, Kusworo Adi, HernowoDanusaputro, Design of a Color Detection Tool to Help Color Blind Patients Based on the Atmega16 AVR Microcontroller, Youngster Physics Journal ISSN : 2302 - 7371 Vol. 1, No. 4, July 2013, Pages 133-142, Faculty of Science and Mathematics, Department of Physics, Diponegoro University.

[6] Sasongko, Bagus Hari, Microcontroller Programming in C. Yogyakarta: Andi, 2012.
[7] Steven F. Barrett, Atmel AVR Microcontroller Programming And Interfacing, First Edition, Colorado (USA): Morgan and Claypool Publishers, 2017.

[8] Young, Thomas, Easy Guide to Simulation \& Practice of Arduino Microcontrollers. Yogyakarta : C.V Andi Offset.. (2016).

[9] YopiMandari, TriyantoPangaribowo. Journal, "Design of a Color-Based Solid Object Sorting Robot System Based on Arduino", Jakarta, 2016. 